\title{
Investigating the Effects of Onion Juice on Male Fertility Factors and Pregnancy Rate After Testicular Torsion/ Detorsion by Intrauterine Insemination Method
}

\author{
Majid Shokoohi $^{1}$, Elahe Olad Saheb Madarek ${ }^{1}$, Arash Khaki ${ }^{*}{ }^{\mathbb{D}}$, Hamed Shoorei ${ }^{1}$, Amir Afshin Khaki ${ }^{1}$, \\ Malihe Soltani ${ }^{2}$, Nava Ainehchi ${ }^{1}$
}

\begin{abstract}
Objectives: In this experimental study, a testicular torsion/detorsion model was used in male rats to investigate the effect of onion juice on male fertility factors and rate of pregnancy by intrauterine insemination (IUI).

Materials and Methods: A total of 56 Wistar rats (28 males vs. 28 females) were included in this study. Male rats were randomly divided into 4 groups including sham, testicular torsion/detorsion, testicular torsion/detorsion treated with onion juice $(40 \mathrm{mg} / \mathrm{kg}$, orally) 30 minutes before detorsion, and those rats that were only treated with onion juice. Treatment with onion juice was continued for 14 days after detorsion. At the end of the study, following anesthesia with ketamine/xylazine ( $5 / 1 \mathrm{mg} / \mathrm{kg})$, levels of testosterone hormone as well as some oxidative stress markers in the blood serum of the male rats were analyzed. Furthermore, sperm parameters were assayed, and then fertility power of the male rats was investigated in the adult female rats using IUI method.

Results: The results of the study showed that there was a significantly negative change in TD group in terms of histological parameters while they were decreased in treated groups. On the one hand, although serum level of malondialdehyde (MDA) significantly increased in TD group, other oxidative markers' (i.e., glutathione peroxidase and superoxide dismutase) serum levels and also testosterone hormone significantly decreased, on the other as compared to the other groups. In addition, the rate of sperm parameters and pregnancy presence were lower in TD group than those of other groups. However, onion juice as a treatment factor could improve the sperm quality and fertility power.

Conclusions: The obtained results revealed that using onion juice could enhance the quality of sperm and fertility power after testicular torsion/detorsion.

Keywords: Torsion/detorsion, Onion, Allium cepa, Testis, Fertility, IUI
\end{abstract}

\section{Introduction}

Infertility is one of the main problems for the couples. According to statistical prevalence, approximately $15 \%$ of the couples are encountered with infertility at the end of the first year of marriage and about $20 \%$ of these cases are occurred in males (1). Furthermore, in recent decades, the number of couples searching for consultation and infertility treatment has increased (2). Although most of the men with infertility have an unusual semen analysis and abnormal sperm parameters, the reasons for infertility are not well described (3). However, according to previously research, these reasons may consist of several parameters such as environmental, dietary, medical, genetic as well as physiological factors (4). Meanwhile, as was first described by MacLeod, reactive oxygen species (ROS) has been considered as one of the most common potential causes of infertility in men (5). Similarly, it was shown that high level of ROS was associated with infertility in up to $40 \%$ of men (4). Besides, other studies in this regard have mentioned that infertility in $30 \%$ to $80 \%$ of men was related to the high level of ROS $(4,6,7)$. Oxidative stress (OS) was found to damage the reproductive system and sperm, and therefore result in reducing sperm motility, lipid peroxidation, and oocyte-sperm fusion in addition to increasing the DNA damage (4). ROS, as stated by several studies, had considerable effects on spermatogenesis and sperm function. They reported that overproduction of ROS had harmful effects on motility, morphology, and concentration of sperm and that it caused sperm DNA damage and apoptosis (4,7-9). Testicular torsion, which occurs due to rotation of testicles, is a pathologic condition that leads to acute scrotal pain. According to the reports, although testicular torsion can be observed in any age group, its peak incidence usually occurs in young males aged 13-16 years. Moreover, it is estimated that 4.5 per 100000 males within the age range of $1-25$ years suffer from spermatic cord torsion (10). Furthermore, as pointed out by some studies, the degree and duration of 
torsion have been considered as two important predictors of testicular damage $(11,12)$, If detorsion was performed within 6 hours of torsion, testicles could be saved in $90 \%$ of the cases; however, if the time of detorsion procedure increased to 12-24 hours, the maintenance rate of testicles decreased to $50 \%$ and $10 \%$, respectively (13). It was also reported that the twisted spermatic cord led to a decrease in/or even complete loss of the perfusion flow to the affected testis and other scrotal contents. Therefore, an emergency surgery for reperfusion of the affected testis was needed. In addition, any attempt to reperfusion of ischemic tissue was considered as the cause of further damage for the testis. For example, damage in the epithelium of seminiferous tubules and loss of germ cells after ischemia/reperfusion (IR) injury of the testis had been reported in some studies $(10,14)$. Moreover, a possible cause of damage in testicles may be a produced ROS during the process of ischemia/reperfusion (15). Nowadays, using a different range of antioxidants has been regarded as a new method in treatment of male infertility. Allium cepa (onion) is one of the natural antioxidants that has been used in traditional medicine for thousands of years. The extract of onion protects sperm against DNA damage and other important molecules related to OS. It also improves sperm quality and enhances the power of fertility (16). Hence, the present study aimed to evaluate the effect of onion juice on rate of male fertility and sperm quality after testicular torsion/detorsion by intrauterine insemination (IUI) in adult female rats.

\section{Materials and Methods}

The present experimental study was carried out on 56 Wistar rats (including 28 adult males vs. 28 adult females) weighed between 250-300 g. Rats were maintained in the animal house of Tabriz University of Medical Sciences under the standard conditions namely, the temperature $23 \pm 2{ }^{\circ} \mathrm{C}$, humidity $60 \%-70 \%$, and a $12 / 12$-hour light/dark cycle while having free access to enough food and water. Male rats were classified into 4 groups $(n=7)$ including sham (G1), testicular torsion for 4 hours followed by surgical detorsion (TD/G2), TD received onion juice (40 $\mathrm{mg} / \mathrm{kg}$, orally) 30 minutes prior to detorsion (TDOJ/G3), and healthy rats that only received $(40 \mathrm{mg} / \mathrm{kg})$ onion juice (OJ/G4).

\section{Surgical Procedure}

In the surgical process, male rats were first anesthetized using ketamine/xylazine $(5 / 1 \mathrm{mg} / \mathrm{kg})$, then left testis was exposed and rotated $720^{\circ}$ counterclockwise by an incision on the scrotum. Afterwards, the tunica albuginea of the torsioned testicle was sutured to the dartos muscle using three $6 / 0$ silk. In addition, the scrotum was closed employing 5/0 silk sutures. The duration of torsion was 4 hours, thereafter another surgery was performed for detorsion. Fourteen days post procedure, all male rats were anesthetized and their blood was drawn from the superior vena cava (IVC) vein, then, the obtained blood was centrifuged at $3000 \mathrm{rpm}$ (for 10 minutes) and afterwards the serum was separated and kept at $-70^{\circ} \mathrm{C}$ to analyze the levels of testosterone hormone and some stress oxidative markers. Moreover, on the last day of the study, that is day 14, male rats underwent bilateral orchiectomy and their left testicles were fixed in Bouin's fluid $(17,18)$.

\section{The Procedure of IUI}

A) Sperm Extraction From Epididymis: after reperfusion period, all male rats were anesthetized, then the tail of epididymis was quickly removed and placed into the $5.0 \mathrm{~mL}$ of phosphate buffer saline (PBS) supplemented with $10 \mathrm{mg} / \mathrm{mL}$ bovine albumin. Several cuttings were made with scissors in the epididymis and the sperm was allowed to get out and float for 5 minutes. Then, some of the suspension was removed to examine the morphology, motility, and count of the sperm. The suspension of sperm was kept in the incubator $\left(37^{\circ} \mathrm{C}\right)$ for 20 minutes until insemination (19).

B) Insemination: female rats were first anesthetized, then the caudal part of the uterus was exposed by an incision in the low midline of the abdomen. The sperm suspension $(0.1 \mathrm{~mL})$ was injected into each horn of uterine lumen and incision was closed with 5/0 silk sutures (19).

\section{Counting of Embryos}

Three days following insemination, female rats were anesthetized with ketamine and xylazine. Fallopian tubes, the rostral portion of uterine horns, and both ovaries were removed and placed in a plate. Then, a 27 -gauge needle was put into the infundibulum of the uterine horn and afterwards, the preimplantation embryos were gathered by PBS flushing and their number was counted under a stereomicroscope. Female rats were considered not pregnant when there were unfertilized oocytes while in the pregnant rats there was at least one embryo (19).

\section{Tissue Preparation}

Removed testicles were placed into falcon tubes, containing Bouin's solution, for 48 hours. Then, the steps of tissue passage were carried out and paraffin embedded testicles were cut and thus, slides with $5 \mu \mathrm{M}$ thickness were prepared. Each slide was stained with hematoxylin and eosin $(\mathrm{H} \& \mathrm{E})$, then examined under an optical microscope (Nikon, Japan) at the magnification of $400 \mathrm{X}$ $(20,21)$.

\section{Histopathological Evaluations}

To evaluate the histological changes in seminiferous tubules of testicles after fixation, the testicles were dehydrated with an ascending ethanol sequence, cleared with xylene and embedded in paraffin. Spermatogenesis in the seminiferous tubules was evaluated with Johnson's score. To this end, 50 seminiferous tubules were randomly selected from each slide and Johnson's score (scales of 
1-10 based on the level of spermatogenesis) was calculated for each tubule. Then, the mean Johnson's score of each case was computed (20). Morphometric studies were conducted on the seminiferous tubules. For this purpose, in each slide, 30 round or nearly round seminiferous tubules were randomly selected, then their morphometry was investigated under the microscope using the linear eyepiece grids at the magnification of 400X. The internal diameter of the seminiferous tubules was measured by the mean average of two perpendicular diameters from the basement membrane on one side of the tubule to the other side of the tubule. The height (thickness) of the germinal epithelium (from base membrane to lumen) was calculated and the data was presented as micrometer $(\mu \mathrm{M})$ (20).

Measurement of Malondialdehyde, Superoxide Dismutase, and Glutathione Peroxidase Serum Levels

The serum levels of Malondialdehyde (MDA), Superoxide Dismutase (SOD), and Glutathione Peroxidase (GPx) were measured based on the previous study conducted by the researchers of the present study (21). Briefly, 200 lambda $(\lambda)$ of serum was poured into a tube containing $3000 \lambda$ of glacial acetic acid, $3000 \lambda$ of $\mathrm{NaOH}(2 \%)$, and tetrabutylamine (TBA, 1\%). Then, the tube was placed into a boiling water bath for 15 minutes. After cooling, the absorbance of the product was read at $532 \mathrm{~nm}$. Moreover, the serum activities of SOD and GPx were measured according to the protocol of the kits (Randox, UK).

\section{Serum Testosterone Measurement}

Serum levels of testosterone were measured according to the protocol of testosterone enzyme-linked immunosorbent assay (ELISA) kit (Demeditec Diagnostices, Germany). The absorbance of the product was read at $405 \mathrm{~nm}$.

\section{Sperm Counting}

The left epididymis was minced in $5 \mathrm{~mL}$ PBS $(\mathrm{pH}=7.2)$. Then, a new solution was made by dissolving $100 \lambda$ of sperm solution in $900 \lambda$ of PBS. At the next step, 1 drop of the solution was poured into the Neubauer chamber and the number of sperm was counted based on the World Health Organization (WHO) protocol $(9,22)$.
Morphology of Sperm

After preparing the smears of sperm for accessing to the morphology, the slides were dried exposing to the air, fixed with alcohol 96\%, and stained with Hand E. Then, in each slide, 150 sperms were randomly counted and therefore, based on the WHO protocol, the percentage of the normal and abnormal sperms were determined $(9,22)$.

\section{Statistical Analysis}

To analyze the data, SPSS (statistical package for the social sciences) software, version 18 (IBM, USA) was used. The normality of data was determined by KolmogorovSmirnov test. In order to compare the data, one-way ANOVA was carried out followed by post-hoc Tukey HSD test and all the data were presented as mean \pm standard error (SE). The level of $P<0.05$ was considered as statistically significant.

\section{Results}

Histopathological Parameters of Testis

Table 1 and Figure 1 show histopathological parameters of the testis. The mean Johnson's score (MJS), the diameter of seminiferous tubules (STD), and the thickness of seminiferous tubule epithelium (HE) significantly decreased in the torsion/detorsion group as compared to the sham group. These parameters increased in treated groups that received onion juice $(P<0.05)$.

\section{Testosterone}

The serum level of testosterone was significantly higher in TD group than that of the sham group $(P<0.05)$. However, in the treated groups, it was significantly higher than TD group (Figure 2).

\section{Oxidative Stress Markers}

In TD group, serum levels of GPX and SOD were significantly declined in comparison with the sham group $(P<0.05)$. In the treated groups, that is, TDOJ and OJ, serum levels of SOD and GPX increased significantly $(P<0.05)$. In addition, although the serum level of MDA was significantly higher in G2 than G1, it decreased $(P \leq 0.01)$ in the treated groups (Table 2$)$.

Table 1. Comparison of Testicular Mean Johnson's Score, Seminiferous Tubule Diameter, and Height of Epithelium in All Groups of the Study

\begin{tabular}{lccc}
\hline Groups & Mean Johnsen's Score & STD & HE \\
\hline Sham & $9.67 \pm .065$ & $267.42 \pm 1.41$ & $72.12 \pm 3.21$ \\
TD & $4.50 \pm .075^{*}$ & $140.80 \pm 1.63^{*}$ & $29.82 \pm 4.32^{*}$ \\
TDOJ & $7.12 \pm 0.045^{\mathrm{a}}$ & $208.75 \pm 7.13^{\mathrm{a}}$ & $57.45 \pm 3.45^{\mathrm{a}}$ \\
OJ & $9.85 \pm 0.075^{\mathrm{a}}$ & $273.52 \pm 4.30^{\mathrm{a}}$ & $75.16 \pm 2.31^{\mathrm{a}}$ \\
\hline
\end{tabular}

Note 1. Sham, control group without the application of tors1ion; TD, testicular torsion/detorsion group; TDOJ, testicular torsion/detorsion, then received $40 \mathrm{mg} / \mathrm{kg}$ of onion juice 30 minutes before detorsion; OJ, healthy rats received $40 \mathrm{mg} / \mathrm{kg}$ of onion juice; STD, seminiferous tubule diameter; $\mathrm{HE}$, height of epithelium.

Note 2 . All the data are displayed as Mean $\pm \mathrm{SE}$; the asterisk $(*)$ and symbol (a) show significant difference with the sham and TD groups, respectively. $*(P<0.05)$. 


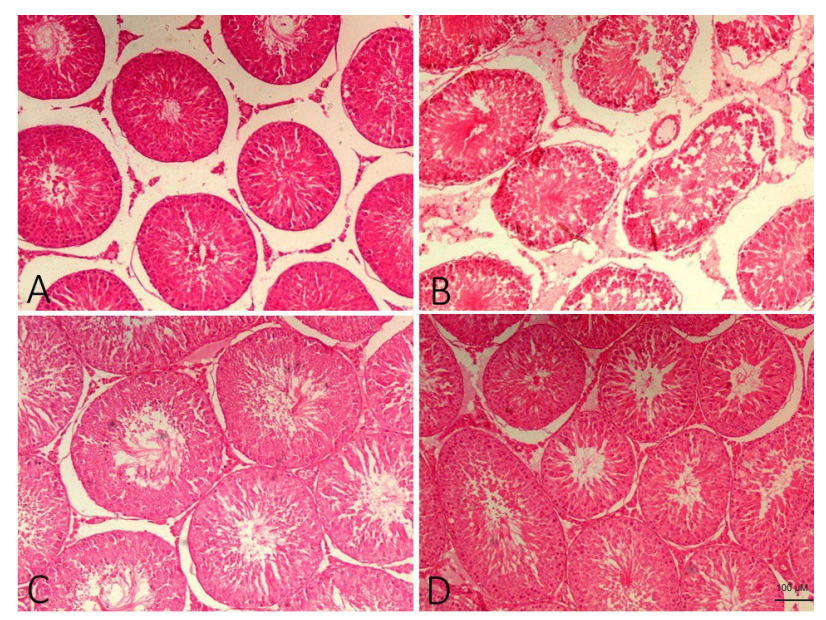

Figure 1: Histological Findings in All Groups of the Study.

Note 1. A: Sham, control group without the application of torsion; B: TD, testicular torsion/detorsion group; C: TDOJ, testicular torsion/ detorsion, then received $40 \mathrm{mg} / \mathrm{kg}$ of onion juice 30 minutes before detorsion; D: OJ, healthy rats received $40 \mathrm{mg} / \mathrm{kg}$ of onion juice. Note 2. Scale bar: $\mathrm{X} 100(100 \mu \mathrm{M})$

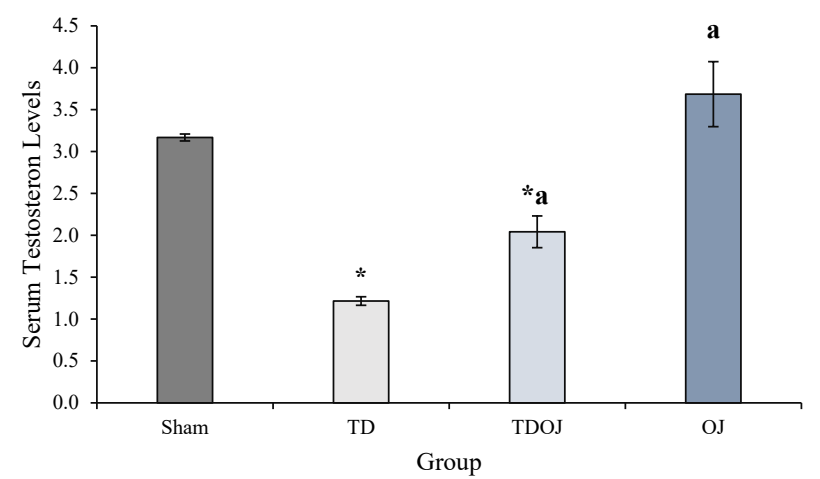

Figure 2: Comparison of Testosterone Levels in All Studied Groups. Note 1. Sham, control group without the application of torsion; TD, testicular torsion/detorsion group; TDOJ, testicular torsion/detorsion, then received $40 \mathrm{mg} / \mathrm{kg}$ of onion juice 30 minutes before detorsion; $\mathrm{OJ}$, healthy rats received $40 \mathrm{mg} / \mathrm{kg}$ of onion juice

Note 2. The asterisk $\left(^{*}\right)$ and symbol (a) demonstrate significant difference with the sham and TD groups, respectively. * $(P<0.05)$

\section{Parameters of Sperm}

Semen analysis in all of the studied groups revealed that there was a significant decrease in the number of sperm in G2 as compared with G1 while in therapeutic groups as compared to G2, it increased significantly $(P<0.02)$. Furthermore, evaluating the morphology of the sperm in different groups indicated that the percentage of abnormal sperm was higher in torsion/detorsion group than that of the sham group. However, in TDOJ and OJ groups, the percentage of abnormal sperm decreased compared to the torsion/detorsion group $(P \leq 0.001)$. Besides, assessment of sperm motility showed that it was significantly lower in $\mathrm{G} 2$ than $\mathrm{G} 1$, but it increased $(P \leq 0.001)$ in the treated groups (Table 3, Figure 3).

The Rate of Pregnancy and the Number of Embryos The pregnancy rate through insemination of sperm in the sham and testicular torsion/detorsion groups revealed that all rats in the sham group were pregnant while in TD group, only one rat, among others, was pregnant; therefore, a significant decrease was observed $(P<0.02)$ in this regard. Moreover, after counting the number of embryos in TD group, a significant difference was observed compared to the sham group $(P<0.01)$. Furthermore, in TDOJ group, 5 rats out of all $(n=7)$ were pregnant while in OJ group, all the rats $(n=7)$ were pregnant; hence, the rate of pregnancy in TDOJ and OJ groups was significantly higher $(P<0.02)$ than TD group (Table 4, Figure 4).

\section{Discussion}

Testicular torsion is one of the main causes of urologic emergency. At the moment, in order to preserve this condition and also preservation of the testis and fertility, quick diagnosis as well as surgical procedure to detorsion are needed (23). The injury of testicles induced by IR



Figure 3. Morphology of the Sperm. Note 1. Symbols a and b show normal and abnormal sperms, respectively; Note 2. Scale Bar: X100 $(100 \mu \mathrm{M})$.

Table 2. Comparison of Sperm Parameters in All the Studied Groups

\begin{tabular}{llll}
\hline Groups & $\begin{array}{l}\text { Concentration } \\
\text { (Mean } \pm \text { SEM) }\end{array}$ & $\begin{array}{l}\text { Normal Morphology } \\
\text { (Mean } \pm \text { SEM) }\end{array}$ & $\begin{array}{l}\text { Normal Motility } \\
\text { (Mean } \pm \text { SEM) }\end{array}$ \\
\hline Sham & $30.45 \pm 2.11$ & $65.65 \% \pm 5.08$ & $63.11 \% \pm 2.31$ \\
TD & $13.25 \pm 3.24^{*}$ & $18.35 \% \pm 2.35^{*}$ & $17.62 \% \pm 3.49^{*}$ \\
TDOJ & $23.55 \pm 2.17^{\mathrm{a}}$ & $54.34 \% \pm 4.21^{\mathrm{a}}$ & $52.71 \% \pm 2.21^{\mathrm{a}}$ \\
OJ & $36.36 \pm 1.08^{\mathrm{a}}$ & $68.46 \% \pm 2.08^{\mathrm{a}}$ & $65.34 \% \pm 3.14^{\mathrm{a}}$ \\
\hline
\end{tabular}

Note 1. Sham, control group without the application of torsion; TD, testicular torsion/detorsion group;TDOJ, testicular torsion/detorsion, then received $40 \mathrm{mg} / \mathrm{kg}$ of onion juice 30 minutes before detorsion; OJ, healthy rats received $40 \mathrm{mg} / \mathrm{kg}$ of onion juice.

Note 2. The asterisk $\left({ }^{*}\right)$ and symbol (a) represent significant difference with the sham group and TD groups, respectively. ${ }^{*}(P<0.05)$ 
Table 3. Comparison of Intrauterine Insemination Results in All the Studied Groups

\begin{tabular}{lccc}
\hline Groups & Pregnancy Rate & Number of Embryo in Left Horne & Number of Embryo in Right Horne \\
\hline Sham & $100 \%$ & $4 \pm 0.81$ & $4 \pm 0.86$ \\
TD & $14.28 \%$ & $0.14 \pm 0.37^{*}$ & $1 \pm 0.89^{*}$ \\
TDOJ & $71.42 \%^{\mathrm{a}}$ & $1.85 \pm 1.46^{\mathrm{a}}$ & $1.85 \pm 1.34^{\mathrm{a}}$ \\
OJ & $100 \%^{\mathrm{a}}$ & $4.42 \pm 1.27^{\mathrm{a}}$ & $4.71 \pm 0.75^{\mathrm{a}}$ \\
\hline
\end{tabular}

Note 1. Sham, control group without the application of torsion; TD, testicular torsion/detorsion group; TDOJ, testicular torsion/detorsion, then received $40 \mathrm{mg} / \mathrm{kg}$ of onion juice 30 minutes before detorsion; OJ, healthy rats received $40 \mathrm{mg} / \mathrm{kg}$ of onion juice.

Note 2 . The asterisk $\left({ }^{*}\right)$ and symbol (a) denote significant difference with the sham group and TD groups, respectively. $*(P<0.05)$

Table 4. Blood Levels of SOD (U/mL), GPX (U/mL), MDA (nM) in Different Groups of the Study

\begin{tabular}{llll}
\hline Groups & $\begin{array}{l}\text { SOD } \\
\text { (Mean } \pm \text { SEM) }\end{array}$ & $\begin{array}{l}\text { GPX } \\
\text { (Mean } \pm \text { SEM) }\end{array}$ & $\begin{array}{l}\text { MDA } \\
\text { (Mean } \pm \text { SEM) }\end{array}$ \\
\hline Sham & $2.07 \pm 0.11$ & $22.74 \pm 5.11$ & $1.78 \pm 0.11$ \\
TD & $0.97 \pm 0.09^{*}$ & $9.34 \pm 7.32^{*}$ & $2.72 \pm 0.29^{*}$ \\
TDOJ & $1.75 \pm 0.17^{\mathrm{a}}$ & $18.24 \pm 4.21^{\mathrm{a}}$ & $1.43 \pm 021^{\mathrm{a}}$ \\
OJ & $2.11 \pm 0.08^{\mathrm{a}}$ & $23.76 \pm 6.08^{\mathrm{a}}$ & $1.42 \pm 0.14^{\mathrm{a}}$ \\
\hline
\end{tabular}

Note 1. Sham, control group without the application of torsion; TD, testicular torsion/detorsion group; TDOJ, testicular torsion/detorsion, then received $40 \mathrm{mg} / \mathrm{kg}$ of onion juice 30 minutes before detorsion; OJ, healthy rats received $40 \mathrm{mg} / \mathrm{kg}$ of onion juice.

Note 2 . The asterisk $\left({ }^{*}\right)$ and symbol (a) show significant difference with the sham group and the TD groups, respectively. ${ }^{*}(P<0.05)$

had been considered as the main pathophysiology of testicular torsion (23). The IR damage can induce a pathophysiologic cascades containing inflammatory responses with extrication of cytokines as well as ROS production (24). One research showed that severity of ischemic histological damage had a direct relationship with the duration and degree of torsion (25). Previous researches on testicular torsion in adult rats demonstrated that duration of 4 hours, $720^{\circ}$ rotation of the spermatic cord, and detorsion caused a significant overproduction in the levels of nitric oxide content, lipid peroxidation, and myeloperoxidase activity (an indicator of neutrophil accumulation) in the testicles $(20,21,26)$. This resulted in the permanent loss of spermatogenesis (27). It has been reported that ischemia followed by reperfusion can induce tissue damages by several mechanisms including increased level of ROS and diffusion of inflammatory factors such as diffusion of apoptotic caspase cascade enzymes


Figure 4. IUI, Intrauterine Insemination in Adult Female Rats. by decreasing the blood flow (26). Similarly, Yuluğ et al reported that ischemia (for 4 hours) and afterward reperfusion injury (for 24 hours) could cause testicular tissue damage (26). Therefore, according to previous studies, the ischemia period was selected 4 hours with 14 days reperfusion. Furthermore, findings of the present study showed that 720 degree ischemia (for 4 hours) and afterward reperfusion (for 14 days) led to severe edema and density of blood vessels. In addition, histopathological examinations revealed that testicular torsion/detorsion resulted in degeneration of germ cells layers and decrease of Johnson's score, the diameter of seminiferous tubules, and the thickness of the epithelium of seminiferous tubules. According to the degenerative damages in testicular tissue induced by torsion/detorsion, it was observed that serum levels of testosterone significantly decreased in testicular torsion/detorsion group. This phenomenon was probably related to the overproduction of ROS, apoptosis of germ cells, and/or injury to the Leydig cells of the testis $(26,27)$. In addition, in the previous study by the authors of the present research, testicular torsion (for 5 hours) followed by detorsion could decrease the serum levels of testosterone (20). In the present study, it was also observed that testicular torsion/detorsion caused a decrease in the quality of sperm including motility and the count of sperm. Moreover, the number of abnormal sperm increased in TD group; this was maybe related to the decrease of testosterone level, apoptosis in testicular germ cells and also ROS production. The results of the current study are in agreement with the findings of the study by Visser et al which showed that testicular torsion 
(for 4 hours) and subsequent reperfusion decreased the quality of sperm (28). Furthermore, Kurcer et al in their study found that testicular ischemia/reperfusion decreased the quality of sperm including a reduction in sperm concentration and an increase in the number of sperm with abnormal morphology and motility (29). Besides, in the present study, following testicular torsion/ detorsion, fertility power by IUI, the rate of pregnancy, and also the number of embryos were measured. However, the pregnancy rate and the number of embryos were significantly decreased in testicular torsion/detorsion group. This probably occurred due to the reduction of serum testosterone level and sperm quality. Additionally, several studies have shown that ROS had deleterious effects on spermatogenesis and sperm function. In other words, the overproduction of ROS could lead to the reduction of sperm concentration and sperm quality $(4,7,8)$.

In the present research, measuring the generalized OS markers (i.e., MDA, SOD, and GPx), the results showed that testicular torsion/detorsion increased the lipid peroxidation (serum level of MDA) and decreased the activities of superoxide dismutase and glutathione peroxidase. Several studies have confirmed that testicular torsion/detorsion increased the OS marker and reduced the levels of antioxidant enzymes $(24,26,27)$.In addition, the results of the previous study by the present researchers showed that testicular torsion (for 5 hours) followed by detorsion increased MDA level and decreased the SOD and GPx activities (20).

The findings of this study demonstrated that onion juice could protect the testis tissue against damages induced by testicular torsion/detorsion. In this regard, the mean Johnson's score, the diameter of seminiferous tubules, and the thickness of the epithelium of seminiferous tubules in treated groups that received onion juice significantly increased as compared to the testicular torsion/detorsion group. It is suggested that antioxidant properties of onion juice and its compounds such as phenolic compositions and flavonoids can prevent overproduction of ROS (30). In the same vein, some studies reported that extract of onion could protect the testis tissue against oxidative damages induced by permethrin (16,30). Besides, Ige et al in their study showed that Allium cepa (AC) could protect the testis tissue against cadmium toxicity (31). The results of this study also demonstrated that onion juice had an improving effect on serum levels of testosterone. The quality of sperm such as the motility, count, and the percentage of normal morphological sperm increased as well. These phenomena may have occurred due to protective effects of onion juice against the damage of the Leydig cells (30). Similarly, one study indicated that onion juice had a positive impacts on the sexual hormones in rats treated with the antiepileptic drug. It also could increase the fertility power (32). In the current study, evaluating the fertility power, it was found that pregnancy rate in
TDOJ and OJ groups increased in comparison with the testicular torsion/detorsion group. In agreement with the results of the present study, khaki et al also reported that the use of onion juice could increase the concentration and motility of sperm and decrease the percentage of sperm with abnormal morphology $(16,30,32)$.

The results of the present study showed that onion juice resulted in a decline of lipid peroxidation (serum level of MDA) and an increase in (SOD and GPx activities. Several studies have confirmed that AC extract can reduce the OS and increase the level of the antioxidant enzyme $(33,34)$.

\section{Conclusions}

According to the findings, it was found that testicular torsion/detorsion, as a urological and emergencial condition, caused testis tissue damage and increased lipid peroxidation level. Moreover, this situation led to a decrease in serum levels of testosterone, sperm quality, and male fertility power. Therefore, it can be concluded that male infertility was one of the most important side effects of testicular torsion followed by detorsion. In addition, consumption of onion juice could protect the testis tissue against damages induced by testicular torsion/ detorsion and increase fertility power of men.

\section{Conflict of Interests}

At the present time, AK acts as the Editor of the journal. As a result of this statement, it is declared that his relation with the journal has affected neither the peer-review process nor the acceptance of the manuscript. The rest declare no conflict of interest.

\section{Ethical Issues}

Tabriz University of Medical Sciences approved the study (with the ethical code of IR.TBZMED.VCR. REC.1397.126).

\section{Financial Support}

This study was financially supported by Women's Reproductive Health Research Center of Tabriz University of Medical Sciences.

\section{Acknowledgments}

The authors would appreciate the stuff of Women's Reproductive Health Research Center of Tabriz University of Medical Sciences.

\section{References}

1. Moradi M, Moradi A, Alemi M, et al. Safety and efficacy of clomiphene citrate and L-carnitine in idiopathic male infertility: a comparative study. Urol J. 2010;7(3):188-193.

2. Rabin DS, Qadeer U, Steir VE. A cost and outcome model of fertility treatment in a managed care environment. Fertil Steril 1996;66(6):896-903.

3. Agarwal A, Sekhon LH. The role of antioxidant therapy in the treatment of male infertility. Hum Fertil (Camb). 
2010;13(4):217-225. doi:10.3109/14647273.2010.532279

4. Ko EY, Sabanegh ES, Jr., Agarwal A. Male infertility testing: reactive oxygen species and antioxidant capacity. Fertil Steril. 2014;102(6):1518-1527. doi:10.1016/j.fertnstert.2014.10.020

5. MacLeod J. The role of oxygen in the metabolism and motility of human spermatozoa. American Journal of Physiology--Legacy Content. 1943;138(3):512-518.

6. Makker K, Agarwal A, Sharma R. Oxidative stress \& male infertility. Indian J Med Res. 2009;129(4):357-367.

7. Tremellen K. Oxidative stress and male infertility-a clinical perspective. Hum Reprod Update. 2008;14(3):243-258.

8. Agarwal A, Sharma RK, Sharma R, et al. Characterizing semen parameters and their association with reactive oxygen species in infertile men. Reprod Biol Endocrinol. 2014;12(1):33. doi:10.1186/1477-7827-12-33

9. Shokoohi M, Shoorei H, Soltani M, Abtahi-Eivari SH, Salimnejad R, Moghimian M. Protective effects of the hydroalcoholic extract of Fumaria parviflora on testicular injury induced by torsion/detorsion in adult rats. Andrologia. 2018:e13047. doi: 10.1111/and.13047.

10. Rabani R, Sadeghipour-Roodsari H, Sepehri H, Dehpour AH-SA. Effect of cannabinoids on testicular Ischemia-reperfusion injury in rat. Acta Medica Iranica. 2006;44(6):365-370.

11. Barada JH, Weingarten JL, Cromie WJ. Testicular salvage and age-related delay in the presentation of testicular torsion. J Urol. 1989;142(3):746-748.

12. Sessions AE, Rabinowitz R, Hulbert WC, Goldstein MM, Mevorach RA. Testicular torsion: direction, degree, duration and disinformation. J Urol. 2003;169(2):663-665. doi:10.1097/01.ju.0000047381.36380.0e

13. Sharp VJ, Kieran K, Arlen AM. Testicular torsion: diagnosis, evaluation, and management. Am Fam Physician. 2013;88(12):835-840.

14. Lysiak JJ, Turner SD, Nguyen QA, Singbartl K, Ley K, Turner TT. Essential role of neutrophils in germ cell-specific apoptosis following ischemia/reperfusion injury of the mouse testis. Biol Reprod. 2001;65(3):718-725.

15. Taati M, Moghadasi M, Dezfoulian O, Asadian P, Zendehdel M. Effects of Ghrelin on germ cell apoptosis and proinflammatory cytokines production in Ischemiareperfusion of the rat testis. Iran J Reprod Med. 2015;13(2):85-92.

16. Khaki A, Rajabzadeh A, Khaki AA. Side Effects of Pyrethroid and Supporting Role of Onion in the Male Rat's Spermatogenesis. Chinese Med J. 2017;130(24):3015.

17. Ozbal S, Ergur BU, Erbil G, Tekmen I, Bagrıyanık A, Cavdar Z. The Effects of $\alpha$-Lipoic Acid against Testicular IschemiaReperfusion Injury in Rats. ScientificWorldJournal. 2012;2012:489248. doi:10.1100/2012/489248

18. Rashed FK, Ghasemi B, Deldade Mogaddam H, Mesgari M. The effect of erythropoietin on ischemia/reperfusion injury after testicular torsion/detorsion: a randomized experimental study. ISRN Urol. 2013;2013:351309. doi:10.1155/2013/351309

19. Cukierski MA, Sina JL, Prahalada S, Robertson RT. Effects of seminal vesicle and coagulating gland ablation on fertility in rats. Reprod Toxicol. 1991;5(4):347-352.
20. Moghimian M, Soltani M, Abtahi H, Shokoohi M. Effect of vitamin $\mathrm{C}$ on tissue damage and oxidative stress following tunica vaginalis flap coverage after testicular torsion. J Pediatr Surg. 2017;52(10):1651-1655.

21. Moghimian M, Abtahi-Evari S-H, Shokoohi M, Amiri M, Soltani M. Effect of Syzygium aromaticum (clove) extract on seminiferous tubules and oxidative stress after testicular torsion in adult rats. Physiol Pharmacol. 2017;21(4):343350 .

22. Benny B, Doss CGP, Kumar DT, Devi SA. Assessing reproductive toxicity and antioxidant enzymes on beta asarone induced male Wistar albino rats: In vivo and computational analysis. Life Sci. 2017;173:150-160.

23. Lee J-W, Kim J-I, Lee Y-A, et al. Inhaled hydrogen gas therapy for prevention of testicular ischemia/reperfusion injury in rats. J Pediatr Surg. 2012;47(4):736-742.

24. Ayan M, Tas U, Sogut E, et al. Protective effect of thymoquinone against testicular torsion induced oxidative injury. Andrologia. 2016;48(2):143-151.

25. Yang C, Song B, Tan J, Liu X, Wei GH. Testicular torsion in children: a 20-year retrospective study in a single institution. ScientificWorldJournal. 2011;11:362-8. doi: 10.1100/ tsw.2011.39.

26. Yuluğ E, Türedi S, Karagüzel E, Kutlu Ö, Menteşe A, Alver A. The short term effects of resveratrol on ischemia-reperfusion injury in rat testis. J Pediatr Surg. 2014;49(3):484-489.

27. Ghasemnezhad R, Mohammadghasemi F, Faghani M, Bahadori MH. Oxytocin can decrease germ cells apoptotic index in testis under acute ischemia reperfusion in a rat model. Iran J Reprod Med. 2015;13(5):283.

28. Visser A, Heyns C. Testicular function after torsion of the spermatic cord. BJU Int. 2003;92(3):200-203.

29. Kurcer Z, Hekimoglu A, Aral F, Baba F, Sahna E. Effect of melatonin on epididymal sperm quality after testicular ischemia/reperfusion in rats. Fertil Steril. 2010;93(5):15451549.

30. Khaki A, Khaki AA, Rajabzadeh A. The effects of Permethrin and antioxidant properties of Allium cepa (onion) on testicles parameters of male rats. Toxin Reviews. 2017;36(1):1-6.

31. Ige SF, Olaleye SB, Akhigbe RE, Akanbi TA, Oyekunle OA, Udoh UAS. Testicular toxicity and sperm quality following cadmium exposure in rats: Ameliorative potentials of Allium cepa. J Hum Reprod Sci. 2012;5(1):37-42. doi:10.4103/09741208.97798

32. Khaki A, Farnam A, Badie AD, Nikniaz H. Treatment effects of onion (Allium cepa) and Ginger (Zingiber officinale) on sexual behavior of rat after inducing an antiepileptic drug (lamotrigine). Balkan Med J. 2012;29(3):236-242. doi:10.5152/balkanmedj.2012.045

33. Achary VMM, Jena S, Panda KK, Panda BB. Aluminium induced oxidative stress and DNA damage in root cells of Allium cepa L. Ecotoxicol Environ Saf. 2008;70(2):300-310.

34. Fatima RA, Ahmad M. Certain antioxidant enzymes of Allium cepa as biomarkers for the detection of toxic heavy metals in wastewater. Sci Total Environ. 2005;346(1-3):256273.

(C) 2018 The Author (s); This is an open-access article distributed under the terms of the Creative Commons Attribution License (http://creativecommons.org/licenses/by/4.0), which permits unrestricted use, distribution, and reproduction in any medium, provided the original work is properly cited. 